\title{
$\ell$-myc Polymorphism in Gastric Cancer, Lung Cancer, and Hepatocellular Carcinoma
}

\author{
Min Su Park, Senior ${ }^{1}$, Sae Bin Jung, Junior ${ }^{1}$, Yeon Hee Park, M.D. ${ }^{2}$, Bong Seog Kim, M.D. ${ }^{3}$, Hyun Ju \\ Park, M.D. ${ }^{4}$, Hee Jae Lee, M.S. ${ }^{1}$, Soon Ae Kim, M.D. ${ }^{1}$, Bong Keun Choe, M.D. ${ }^{1}$ and Joo Ho Chung, M.D. \\ ${ }^{1}$ Kohwang Medical Research Institute, College of Medicine, Kyung Hee University; ${ }^{2}$ Division of Medical Oncology, Korea \\ Cancer Center Hospital; ${ }^{3}$ Division of Medical Oncology, Seoul Veterans Hospital, Seoul; ${ }^{4}$ Division of Gastroenterology, \\ College of Medicine, Hallym University, Pyungchon, Korea
}

Purpose: This study was performed to see if a particular polymorphism in the $\ell-m y c$, a nuclear oncogene at the 1 p32 locus, might be associated with greater risk of gastric cancer, lung cancer and hepatocellular carcinomas ( $\mathrm{HCC}$ ) in Korean patients.

Materials and Methods: Genomic DNA, derived from patients diagnosed with gastric cancer $(n=57)$, lung cancer $(n=39), \operatorname{HCC}(n=35)$ and healthy individuals $(n=$ 176), was examined. The $\ell$-myc polymorphism under study was visualized by PCR followed by EcoRI digestion.

Results: There was no significant difference in the

\section{INTRODUCTION}

Gastric cancer, lung cancer, and hepatocellular carcinomas (HCC) are major causes of cancer-related deaths in Koreans. Previous studies have tried to identify possible genetic markers for the assessment of individual risk to gastric cancer, lung cancer and HCC. Several epidemiological, pharmacogenomic and genetic studies have postulated the possibility of an inherited predisposition to gastric cancer, lung cancer and HCC $(1 \sim 6)$. Activating proto-oncogenes, and turning them into oncogenes, is an important mechanism of the initiation and progression of tumorigenesis (7). Previous studies have suggested that allelic variation of proto-oncogenes, such as $\ell-m y c$, a nuclear oncogene at the $1 \mathrm{p} 32$ locus, might predispose individuals towards tumor development $(8 \sim 10)$, implying that such variant alleles may serve as markers for genetic susceptibility to cancer.

Recently, polymorphisms of the $\ell$-myc gene have been investigated in various types of cancer $(10 \sim 19)$. However, the results from these investigations have not always been

Correspondence: Joo Ho Chung, Kohwang Medical Research Institute, Kyung Hee University College of Medicine, 1 Hoegi-dong, Dongdaemun-gu, Seoul 130-701, Korea. (Tel) + 82-2-961-0281, (Fax) +82-2-968-0560, (Email) jhchung@ khu.ac.kr

Received May 28, 2002, Accepted October 23, 2002 distribution of the $\ell$-myc polymorphism genotypes and allele frequencies between the cancer patients and the controls.

Conclusion: The $\ell$-myc polymorphism does not appear to be indicative of elevated risk of cancers of the stomach, lung and HCC. (Cancer Research and Treatment 2002;34: 436-438)

Key Words: Gastric neoplasm, Lung neoplasm, Hepatocellular carcinoma, $\ell-m y c$ polymorphism

consistent $(9,12)$. Moreover, these studies have not investigated the potential utility of the $\ell$-myc polymorphism as a genetic marker in the Korean population.

In this study, we have examined if alleric variants of the $\ell$-myc gene are associated with an increased risk for gastric cancer, lung cancer and HCC in the Korean population.

\section{MATERIALS AND METHODS}

\section{1) Patient selection}

Our sample population comprised of 57 patients diagnosed with gastric cancer, 39 with lung cancer, 35 with HCC, and 176 normal individuals, all of Korean ethnicity. The average age of patients was 42 years, ranging from 16 to 79 years of age; lung cancer: 66 , stomach cancer: 62 , HCC: 56 . The control group ages were adjusted according to relate to those of the patients. Informed consents were gained from all the lung cancer, hepatocellular carcinoma and stomach cancer cases. Blood samples were obtained without any particular exclusion criteria. All the control patients had to have no previous history of cancer, and were in sufficiently good condition to provide a blood sample.

\section{2) PCR-RFLP analysis of $\ell$-myc}

Genomic DNA was extracted from peripheral blood leukocytes according to routine procedures. The polymorphism in the 2nd intron of the $\ell-m y c$ gene was amplified using primers that flank the polymorphic EcoR I site, as described below (9): 
10 pmol of each primer (5'-AGTTCACTCACAGGCCACAT-3' and 5'-TGCATATCAGGAAGCTTGAG-3'), $2.5 \mathrm{mM}$ of dNTP, 2 units of Taq polymerase (Takara, Shiga, Japan) and $3 \mu l$ of 10X PCR buffer were mixed together, and the restriction volume was brought up to 30pl with $\mathrm{ddH}_{2} \mathrm{O}$. The PCR products were digested with EcoRI (Roche, Mannheim, Germany) at $37^{\circ} \mathrm{C}$ overnight, which was followed by electrophoresis on a $2.5 \%$ agarose gel containing ethidium bromide for visualization.

\section{3) Statistical analysis}

Statistical analysis of differences of the genotypic and allelic frequencies of the polymorphic forms of the $\ell-m y c$ gene, between the patients and the control subjects, was determined using the $x^{2}$ test. $\mathrm{P}<0.05$ was considered to be indicative of statistical significance.

\section{RESULTS}

The characteristics of the patients and controls are shown in Table 1. All the cancer patients had biopsy proven malignancies, and lung cancer pathologic subtypes were shown (NSCLC; 31 cases, SCLC; 8 cases).

The bands corresponding to the polymorphic fragments of

Table 1. Characteristics of cancer patients and control subjects

\begin{tabular}{lrrr}
\hline & & Case & Control \\
\hline Total (n) & & 131 & 176 \\
Stomach cancer & & 57 & \\
\multicolumn{2}{c}{ (adenocarcinoma) } & 31 & \\
Lung cancer & NSCLC & 8 & \\
Hepatocellular & SCLC & 35 & \\
$\quad$ carcinoma & & 108 & 90 \\
Gender & Male & 23 & 86 \\
& Female & 2 & 96 \\
Age & $<40$ & 16 & 69 \\
& $40 \sim 49$ & 36 & 10 \\
& $50 \sim 59$ & 44 & 1 \\
& $60 \sim 69$ & 33 & 0 \\
\hline
\end{tabular}

each $\ell$-myc EcoRI genotype read as follow. Two alleles were observed upon EcoRI digestion: the ' $L$ ' allele, corresponding to the $267 \mathrm{bp}$ fragment, and lacking the EcoRI site, and the ' $\mathrm{S}$ ' allele, corresponding to the $142 \mathrm{bp}$ and $125 \mathrm{bp}$ fragments, produced from the cleavage at the EcoRI site. The alleles were made up of three genotypes, LL (the $267 \mathrm{bp}$ fragment only), LS (three fragments, the $267 \mathrm{bp}, 142 \mathrm{bp}$ and $125 \mathrm{bp}$ fragments) and SS (two segments, the $142 \mathrm{bp}$ and $125 \mathrm{bp}$ fragments) (Fig. 1).

The LL : LS : SS ratios (ratio of the genotypes) were 22 : $26: 9,17: 20: 2$ and $17: 16: 2$ in the gastric cancer, lung cancer and HCC patient groups, respectively (Table 2). There were no significant differences in the $\ell$-myc genotype distribution and allele frequencies between the cancer patients and the healthy individuals. To determine any possible association between the $\ell$-myc genotype and the risk of histological types of lung cancer, cases were divided into two groups according to their pathological classification. No differences were seen in the $\ell$-myc genotype distribution between the two groups, but because the sample size was small, proper risk determination was insufficient.

\section{DISCUSSION}

Recently, studies for various cancer risk and polymorphisms of candidate genes have been reported, for which epidemiological and clinicopathological associations with genetic susceptibility to cancer were discussed $(20 \sim 22)$.

In the present report, a genotypic association study was performed to investigate a possible relationship between the Ł-myc EcoRI polymorphism and susceptibilities to gastric cancer, lung cancer and HCC.

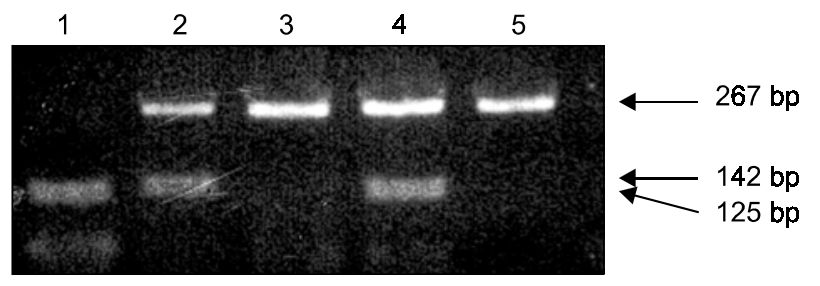

Fig. 1. Representative photos of genetic polymorphism analysis representing the three patterns of genotypes. Homozygote LL allele (Lane 3, 5), Heterozygote LS allele (Lane 2, 4), Homozygote SS allele (Lane 1) for L-myc EcoRI RFLP.

Table 2. Distribution of polymorphism of $\ell-m y c$ among gastric cancer, lung cancer, and hepatocellular carcinoma (HCC) patients and controls

\begin{tabular}{|c|c|c|c|c|c|c|c|c|c|}
\hline \multirow{2}{*}{ Group } & \multicolumn{5}{|c|}{$\ell-m y c$ genotype } & \multicolumn{4}{|c|}{$\ell-m y c$ allele } \\
\hline & LL & LS & SS & $\mathrm{X}^{2}$ & $P$ & $\mathrm{~L}$ & S & $\mathrm{X}^{2}$ & $\mathrm{P}$ \\
\hline Gastric cancer & $22(0.39)$ & $26(0.46)$ & $9(0.15)$ & 0.90 & 0.64 & 70 & 44 & 0.08 & 0.78 \\
\hline Lung cancer & $17(0.44)$ & $20(0.51)$ & $2(0.05)$ & 2.84 & 0.24 & 54 & 24 & 2.33 & 0.13 \\
\hline $\mathrm{HCC}$ & $17(0.49)$ & $16(0.46)$ & $2(0.05)$ & 3.60 & 0.16 & 50 & 20 & 3.26 & 0.07 \\
\hline Controls & $59(0.33)$ & $93(0.53)$ & $24(0.14)$ & & & 211 & 141 & & \\
\hline
\end{tabular}


Several previous studies have examined the frequencies of $\ell$-myc genotypes in various types of human cancer, such as gastric $(14,19)$, lung $(13,16)$, colorectal $(12,17)$, HCC $(10)$, oral (15), breast (19), renal (11) and bone or soft tissue sarcomas (18), for possible association between various polymorphisms and cancer susceptibility.

It remains controversial as to whether the $\ell-m y c$ polymorphism may affect the susceptibility to tumors. Kato et al (18) reported an association between the SS genotype and susceptibility to bone and soft tissue sarcomas in male patients, but no such association was found with lymphoma, leukemia or breast cancer. Taylor et al (10) reported a protective effect of the SS genotype in HCC.

In the present study, there were no significant differences in the genotypic and allele frequencies of the $\ell-m y c$ gene between the cancer patients and the controls.

\section{CONCLUSIONS}

The $\ell$-myc EcoRI polymorphism may not be associated with increased susceptibility to gastric cancer, lung cancer or HCC.

\section{REFERENCES}

1. Ayesh R, Idle JR, Ritchie JC, Crother MJ, Hetzel MR. Metabolic oxidation phenotypes as markers for susceptibility to lung cancer. Nature 1984;312:169-170.

2. Caporaso NE, Tucker MA, Hoover R, Hayes RB, Pickle LW, Issaq $\mathrm{H}$, Muschik G, Green-Gallo L, Buivys D, Aisner S, Resau J, Trump BF, Tollerud D, Weston A, Harris CC. Lung cancer and the debrisoquine metabolic phenotype. J Natl Cancer Inst 1990;85:1264-1272.

3. Harris CC, Mulvihill JJ, Thorgirsson SS, Minna JD. Individual difference in cancer susceptivility. Ann Intern Med 1980;92: 809-825.

4. Kountouras J, Lygidakis NJ. New epidemiological data on liver oncogenesis. Hepatogastroenterology 2000;47(33):855-861.

5. Becker KF, Keller G, Hoefler H. The use of molecular biology in diagnosis and prognosis of gastric cancer. Surg Oncol 2000; 9(1):5-11.

6. Park JW, Song YJ, Yun HY, Kim H, Ahn YO, Kim SJ, Kim JP, Kang JW, Nam HM, Kim YD. The risk of gastric cancer in Korean according to smoking, drinking, diet, and the genetic polymorphisms of glutathione S-transferases and L-myc protooncogene. J Korean Cancer Assoc 2000;32:997-1006.

7. Bishop, JM. Molecular themes in oncogenesis. Cell 1991;64: 235-248.

8. Champeme MH, Bieche I, Latil A, Hacene K, Lidereau R. Association between restriction fragment length polymorphism of the $\ell$-myc gene and lung metastasis in human breast cancer. Int J Cancer 1992;50:6-9.

9. Tamai S, Sugimura H, Caporaso NE, Resau JH, Trump BF, Weston A, Harris CC. Restriction fragment length polymorphism analysis of the $\ell$-myc gene locus in a case-control study of lung cancer. Int J Cancer 1990;46:411-415.

10. Taylor JA, Bell DA, Nagorney D. $\ell$-myc proto-oncogene alleles and susceptibility to hepatocellular carcinoma. Int $\mathbf{J}$ Cancer 1993;54:927-930.

11. Kakehi Y, Yoshida O. Restriction fragment length polymorphism of the $\ell$-myc gene and susceptibility to metastasis in renal cancer patients. Int J Cancer 1989;43:391-394.

12. Ikeda I, Ishizaka Y, Ochiai M, Sakai R, Itabashi M, Onda M, Sugimura T, Nagao M. No correlation between $\ell$-myc restriction fragment length polymorphism and malignancy of human colorectal cancers. Jpn J Cancer Res 1988;79:674-676.

13. Kawashima K, Nomura $S$, Hirai H, Fukushi $S$, Karube $T$, Takeuchi K, Naruke T, Nishimura $S$. Correlation of $\ell$-myc RFLP with metastasis, prognosis and multiple cancer in lung cancer patients. Int J Cancer 1992;50:557-561.

14. Mironov NM, Aguelon AM, Potapova GI, Gorbunov OV, Klimenkov AA, Yamasaki $\mathrm{H}$. $\ell$-myc allele polymorphism and prognosis for metastasis in Russian gastric cancer patients. Eur J Cancer 1994;30A:1732.

15. Saranath D, Panchal RG, Nair R, Mehta AR, Sanghavi V, Deo MG. Restriction fragment length polymorphism of the $\ell$-myc gene in oral cancer patients. Br J Cancer 1990;61:530-533.

16. Tefre T, Borresen AL, Aamdal S, Brogger A. Studies of the $\ell$-myc DNA polymorphism and relation to metastasis in Norwegian lung cancer patients. Br J Cancer 1990;61:809-812.

17. Young J, Buttenshaw R, Buttenshaw L, Ward M, Searle J, Leggett B, Chenevix-Trench G. Association of the SS genotype of the $\ell$-myc gene and loss of $18 \mathrm{q}$ sequences with a worse clinical prognosis in colorectal cancer. Oncogene 1994; 9:1053-1056.

18. Kato M, Toguchida J, Honda K, Sasaki MS, Ikenaga M, Sugimoto M, Yamaguchi T, Kotoura Y, Yamamuro T, Ishizaki $\mathrm{K}$. Elevated frequency of a specific allele of the $\ell$-myc gene in male patients with bone and soft tissue sarcomas. Int J Cancer 1990;45:47-49.

19. Ishizaki $\mathrm{K}$, Kato $\mathrm{M}$, Ikenaga $\mathrm{M}$, Honda $\mathrm{K}$, Ozawa $\mathrm{K}$, Toguchida J. Correlation of $\ell$-myc genotypes to metastasis of gastric cancer and breast cancer. J Natl Cancer Inst 1990;82: 238-239.

20. Gonzalez CA, Sala N, Capella G. Genetic susceptibility and gastric cancer risk. Int J Cancer 2002;100:249-260.

21. Lewis SJ, Cherry NM, Niven RM, Barber PV, Povey AC. GSTM1, GSTT1 and polymorphisms and lung cancer risk. Cancer Lett 2002;180:165-171.

22. Ariyoshi N, Miyamoto M, Umetsu Y, Kunitoh H, DosakaAkita H, Sawamura Y, Yokota J, Nemoto N, Sato K, Kamataki T. Genetic polymorphism of CYP2A6 gene and tobacco-induced lung cancer risk in male smokers. Cancer Epideiol Biomarkers Prev 2002;11:730-738. 